INTERNATIONAL DESIGN CONFERENCE - DESIGN 2018

https://doi.org/10.21278/idc.2018.0494

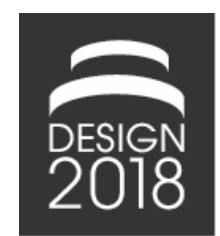

\title{
A PRODUCT SUCCESS SCALE FOR SUPPORTING RESEARCH IN ENGINEERING DESIGN
}

\author{
L. Maccioni and Y. Borgianni
}

\begin{abstract}
Although product design targets success, the achievement of success is rarely verified or insightfully explored because of difficulties in measuring this term. The present paper addresses design research by proposing a procedure to extrapolate success of products by means of the vast knowledge made available by the scientific literature and the Internet at large. The final achievements are constituted by an algorithm to perform information search about product success and a success scale to be used as an ordinal variable in a posteriori studies involving large numbers of products.
\end{abstract}

Keywords: product success, product failure, product development, information retrieval, sustainable design

\section{Introduction}

More or less openly, design initiatives target the achievement of success with regard to products that have to be developed. Design research studies whether certain practices, methods, tools and procedures effectively contribute to the pursuance of initially posed objectives. In order to perform these studies, a clear and shared definition and characterization of success are lacking, e.g. (Moatari Kazerouni et al., 2011), and might result supportive, especially in the academic arena.

From an industrial perspective, success is a goal to accomplish in terms of market and competitiveness results. From an academic point of view, factors influencing success are mostly investigated; it is therefore understood as the outcome of events, proposals, choices and decisions, which are analysed to infer best practices (Bender and Marion, 2016; Machado, 2016). For this reason, in order to investigate how and which factors affect product success, scholars have attempted to provide explanations through empirical studies on existing products (Dinter, 2013; Hernandez et al., 2014). With the aim to find patterns that can correlate product features and design strategies with success, empirical studies have been conducted (Borgianni et al., 2013; Troxell and Kim, 2016) and will be presumably carried out in the future. The relationship between fulfilled success indicators and the analysed product characteristics is often statistically supported in order to extrapolate guidelines for managers and designers in the New Product Development (NPD) field (Borgianni et al., 2013; Song et al., 2015).

Challenges of these research approaches include, in addition to the demonstration of the relevance of specific success drivers, the possibility to assert with certainty whether a product is a success or not (Song et al., 2015). The determination of product success is indeed troublesome as it depends on firms' or designers' goals (Maidique and Zirger, 1985), which are not normally not revealed. Apart from the possible misalignment between design goals and market-related outputs (used more widely), these data are seldom available for at least two reasons. On the one hand, publicly available financial results, e.g. enterprises' budget, commonly refer to firms and not to specific products. On the other hand, the secrecy of these data is a clear asset of firms. 
Given these disadvantages, the authors propose to leverage literature and web information to infer product success and to characterize it with a plurality of nuances, as remarked in Section 2. More specifically, success is intended as a manifestation of product performances in terms of market results or social impact, not as a dimension of technical performances - a certain artefact might fulfil initial design requirements and display excellent quality, but not thrive at the same time. The objective is to introduce a procedure that can be considered valid for each specific product or service (featured e.g. by peculiar characteristics, trademark) irrespective of their complexity, industry or time of launch in the market; however, limitations for too recent designs are pointed out in the residual of the paper. The proposed procedure and characterization (Section 3) makes it possible to define classes of product success, which could be used as nominal variables by researchers. This is possible although affected by the criteria used to satisfy certain conditions (Section 4). Eventually, a success scale has been proposed to feature success as an ordinal variable. The reliability of the scale is confirmed thanks to a test that has involved experts in engineering design and product development management (Section 5). Section 6 draws conclusions, introduces future work and remarks current limitations of the procedure.

\section{Background}

With a specific reference to business literature, the necessity is once again stressed to know entrepreneurs' objectives, innovation strategies and business models in order to evaluate if a product can be referred as a success (Hultink and Robben, 1995; Griffin and Page, 1996). This implies that, apart from a few exceptions where the achievement of success is straightforward to many respects, its evaluation might benefit from general criteria that are leveraged irrespective of firms' internal objectives. Research in this specific area has flourished in the 1980s and 1990s, while no reference contributions have been found that are published in the present century - this has emerged also in (Moatari Kazerouni et al., 2011). It seems like that this branch of research has been neglected recently, although no conclusive and shared output has surfaced. Success evaluation is carried out through a variety of success indicators available in the literature (Cooper and Kleinschmidt, 1987; Griffin and Page, 1993; Hart, 1993). Success has therefore a multidimensional nature and, more markedly, the indicators used to assess it are neither agreed nor interpreted unanimously. For instance, the achievement of satisfying sales levels opens up new business opportunities in (Cooper and Kleinschmidt, 1987), indicates a measure of new products' acceptance in (Griffin and Page, 1993) and represents just a financial index in (Hart, 1993). Success indicators are both of financial (market share, revenues, ROI, etc.) and non-financial nature (Hart, 1993), with the latter being particularly stressed in (Cooper and Kleinschmidt, 1987). Given the plethora of these success indicators (75 according to Griffin and Page (1993)), the literature tends to agree that not all of them have to be necessarily fulfilled in order to consider a product as a success. Still according to (Griffin and Page, 1993), enterprises could focus on certain success dimensions and overlook others as they might result conflicting. In light of this contradicting situation, it could result useful to prioritize certain dimensions over others, but also in this case, no agreement has emerged. Consequently, the selection of appropriate indicators to consider might be, on its turn, based on the goals set by scholars who analyse product success and, thus, arbitrary to a considerable extent.

The objective of this paper is to limit the subjectivity of success assessment performed by researchers in product design by benefitting from the huge amount of information available nowadays, which was not surely present at the time of the mainstream research on this topic.

The exploitation of literature knowledge to determine product success is not a new approach in the field (Borgianni et al., 2013). In the latter contribution, a distinction between successful products/services and unsuccessful experiences was made in order to compare different designs targeting radical innovation. A set of new value propositions was chosen by the scholars and attention was paid to balance the number of successes and fiascos. In certain circumstances, the set of products cannot be selected a priori with the same freedom. This can result in unbalances between the number of thriving businesses and failures, as the former are preferentially presented in the literature to prove concepts (Haig, 2005; Borgianni et al., 2013). Such unbalances might eventually jeopardize statistical analyses or make the extraction of significant success drivers more difficult. In addition, when product sets are assigned, it is likely that direct information about many examples is not available despite the abundant knowledge that the Internet makes accessible. 
To this respect, the search for information about product success might not be limited to the identification of sources stating that a specific product is thriving/failing in the marketplace or exhibits excellent performances valued by consumers. Indeed, several indicators are proposed that can be considered as symptoms of successful/unsuccessful products, including those introduced in the above literature. The authors have attempted to collect non-financial indicators more viable to be identified in Internet searches, which are discussed in the followings.

If success is intended as the capability of a product to "leave track", as opposed to artefacts consigned to oblivion (Hsiao et al., 2017), this can be detected through a variety of phenomena. In the design field, Faerber and Carbon (2013) highlight how many firms try to replicate product features of successful innovators. It follows that the existence of imitations represents a clear manifestation of product success. Other effects are visible when an innovation demonstrates to be influential in the history of product development. For instance, the birth of complementary products as an evidence of success is remarked by many scholars in the last few decades (McGee and Sammut Bonnici, 2002; Rainer and Strohmaier, 2014; Calcei and Ohana, 2017). As the impact of successful artefacts can be understood also as a technical, and not just as a market-related, breakthrough, many scholars associate the achievement of patent protection of commercialized products with the emergence of success (Nyström, 1985; Hart, 1993). An indication of products' interest in specific domains is also seen as a potential carrier of success. The accomplishment of special recognition, e.g. design awards (Hart, 1993; Lockwood, 2007) is a case in point. However, some sources suggest that the achievement of design awards might not necessarily result in plain market success; some examples of this kind are reported in (Rampino, 2011). Therefore, product recognition in circumscribed environments might not be associated to the uncontested demonstration of success; at least, this is not comparable to the success reported by mass-market products. The generalization of this concept leads to identify certain categories of products with a restricted extent of success. These might include artefacts for museum exhibition only or products that have thrived in extremely limited niche markets.

\section{Methodological approach}

The overall goal of the paper is therefore to support the assessment of products' success based on information at everybody's disposition. The search and consequent exploitation of this information might benefit from rules and criteria in order to make success assessment more rigorous and repeatable. In this sense, the authors aimed to systematize a logical procedure for browsing scientific literature and the web. The considerations reported in the background, with specific reference to success indicators and criteria to infer success, were properly taken into account. However, the whole procedure cannot be fully standardized as any researcher willing to evaluate success of many product might will to customize several aspects according to their needs and objectives. This will become more apparent in the followings, as the authors will present the structure of the proposed procedure and, at the same time, the recalled aspects subjected to choices based on the researcher's scopes and experience. Authors' specific choices will be then revealed.

This section is divided into three subsections in order to emphasize the need to fundamentally establish:

- Which sources to explore in order to find exhaustive data, Subsection 3.1;

- What is necessary to define for achieving the search goal, Subsection 3.2;

- How to perform the search through a systematic logic, Subsection 3.3.

\subsection{Definition of search databases}

The first step of the procedure is to specify where product information should be detected. This can include scientific databases, search engines and specific networks, e.g. social networks. In the followings, those items will be referred as databases for the sake of simplicity. Of course, the larger the number of databases to be considered, the higher the exhaustiveness of the information search. However, leveraging too general databases can affect the reliability of the gathered information negatively. Therefore, it is appropriate to organize these databases in a hierarchical way based on their importance and/or reliability. In this way, the consideration of multiple databases increases the chances of finding the required information; contextually, a hierarchy allows scholars to assign priorities and, then, to collect information with different levels of importance/reliability. By consulting databases, the most desirable result would 
be the identification of clear statements about either the success/failure of a product or outstanding/miserable market performances. This aspect is treated in the next subsection more in detail. Nevertheless, as information concerning indirect indicators (discussed in Section 2) can be seen as a means to evaluate success as well, it is also important to establish the databases where it is plausible, appropriate and easier to find such a kind of information. For instance, the readers might overall evaluate the databases with different priorities and scopes as illustrated in Table 1. In This table, it is possible to notice how priorities are classified through an $\mathrm{N}$-index. Still in the table, $\mathrm{N}^{*}$ features the database with the lowest priority where it is possible to find both direct and indirect information about success. From $\mathrm{N}^{*+1}$ until $\mathrm{N \#} \mathrm{(featuring} \mathrm{the} \mathrm{lowest} \mathrm{hierarchy} \mathrm{level),} \mathrm{only} \mathrm{databases} \mathrm{are} \mathrm{clustered} \mathrm{useful} \mathrm{for} \mathrm{finding}$ indirect success information. The Table 1 presents authors' preferences, based on empirical tests conducted beforehand. Obviously, the reader can select different databases and priority scales.

Table 1. Illustrative determination of databases for the search of information about product success

\begin{tabular}{|c|c|l|c|}
\hline Priority N & $\begin{array}{c}\text { Database } \\
\text { example }\end{array}$ & \multicolumn{1}{|c|}{ Aims } & $\begin{array}{c}\text { Kind of success- } \\
\text { related information }\end{array}$ \\
\hline 1 & Scopus & To carry out a systematic scientific bibliographic search & Direct/Indirect \\
\hline 2 & Google Scholar & To get a broader overview of existing literature & Direct/Indirect \\
\hline$\ldots \ldots$ & $\ldots \ldots$ & $\ldots \ldots$. & Direct/Indirect \\
\hline $\mathrm{N}^{*}$ & Google Search & $\begin{array}{l}\text { To maximize the information coverage. Empirically, it is } \\
\text { especially useful for identifying information about } \\
\text { failures, otherwise poorly treated in the literature }\end{array}$ & Direct/Indirect \\
\hline $\mathrm{N}^{*}+1$ & Google Images & To find imitations or similar products & Indirect \\
\hline$\ldots \ldots$ & $\ldots \ldots .$. & $\ldots .$. & Indirect \\
\hline $\mathrm{N} \#-1$ & Esp@cenet & To make a comprehensive and structured patent search & Indirect \\
\hline $\mathrm{N} \#$ & Amazon & To individuate imitations or complementary products & Indirect \\
\hline
\end{tabular}

\subsection{Success/failure criteria}

According to the proposed investigation procedure, the definition and characterization of product success is based on the fulfilment of several conditions. These deal with the individuation of specific information, available in the chosen databases, which concerns the development and evolution "history" of analysed products. The recalled conditions are verified according to the answers given to the questions that are introduced by the titles of the subparagraphs that follow. The authors claim that an insightful investigation of product success has to be made by means of such questions, which plainly and deliberately aim to investigate success manifestation in general and the success indicators described in Section 2. Of course, the completeness of the questions depends on the completeness of success indicators achievable from generally available information; the authors consider the background description reported in Section 2 as exhaustive. However, the way to determine if the questions are answered in an affirmative way might depend on criteria that are not universal and that are to be established by a researcher beforehand. After the presentation of the questions and the corresponding conditions to be verified, the authors propose illustrative examples of the mentioned criteria, summarized in Table 2.

\subsubsection{Can any product be investigated adequately?}

At a first instance, the availability of product-related information is to be checked. Indeed, missing information about the product suggests a specific characterization of achieved success. If no (or very scarce) information about the product is found in the predefined databases, the product can be considered as consigned to oblivion. If product information is found but not useful to assign success or failure, then the product is not evaluable. It is advantageous to check that product information is present in the selected databases before launching any search on success. This control can be referred as "Research Necessary Condition" (RNC).

At the same time, a sort of filter is worth establishing that allows the researcher to discard products that would not lead to reliable results. More specifically, the generation of a logic of time-based exclusion 
is plausible; if the product is too recent, relying on information about its stated performances and success results hazardous. Otherwise said, the product has not to be "too recent", because the comparison with mature products will be significantly biased. Obviously, the subjectivity of defining "too recent" varies according to the product category, but establishing a threshold value increases the traceability of choices made. For example, bibliographic sources suggest that a NPD process lasts an average of four years (Bourgeon, 2007). However, it has to be pointed out that, according to the expected use of the success characterization, i.e. a posteriori investigations of samples of products and designs, it is unlikely that such a sample includes products for which the level of maturity is low, especially if this set is extracted from published collections on its turn.

Hence, the initial conditions to be checked are RNC and MNC, i.e. the necessary conditions the product has to meet in order to continue in the success characterization process. At this step, the subjectivity of the researcher basically involves the consideration of the sufficiency of information and the fact to evaluate the product mature enough for subsequent success evaluations.

\subsubsection{Is there information that can undoubtedly enable the characterization of a product as success/failure?}

In order to answer this question, the "Success Sufficient Condition" (SSC) and "Failure Sufficient Condition" (FSC) are defined. These sufficient conditions allow the researcher to assert product success or failure based on the identification of specific information in certain databases or the fulfilment of a particular condition. The explicit affirmation of the product success in a scientific source can be considered as a SSC according to a logical criterion that can be introduced. Conversely, an example of FSC is retrieved information about a product remained to a prototype level for a "long enough period" with no prospects of industrial development. Logically, other information can be considered sufficient to state product success or failure; it depends on the goal of the characterization and the decisions made by researchers.

\subsubsection{Is there any necessary information for stating success/failure?}

As Subsection 3.3 will better illustrate, the conditions presented in this subsection are viable to be investigated in light of the lack of sufficient conditions introduced in 3.2.2.

The researcher has to identify the necessary conditions for stating the product success/failure, namely the "Success Necessary Condition" (SNC) and the "Failure Necessary Condition" (FNC), respectively. For example, FNC can be addressed by the presence of information, in the explored databases, in terms of insufficient performances, not achieved goals, unfulfilled expectations. SNC can be featured by the fulfilment of commonly agreed success indicators.

Moreover, it is essential to establish the supplementary conditions that permit to assert the emergence of success (failure), when the SNC (FNC) are met. As it will be better explained in the followings, SNC and $\mathrm{FNC}$ are not mutually exclusive; conversely, the individuation of information suggesting success and failure is frequent in authors' experience. In this sense, the presence of the SNC (FNC) and the absence of the FNC (SNC) can be seen as an evidence of success (failure).

\subsubsection{Is the reliability of information about success/failure to be considered equally irrespective of the sources in which this information is found?}

With the aim to answer this question, it is essential to remind that information about failure is found more seldom than that about success. For this reason, if information is found about the FNC but not about the $\mathrm{SNC}$ in the same database, a logical choice would be to consider the product as a failure. If, during the retrieval of information in a database, SNC emerges while FNC does not, it is recommended to continue the investigation by browsing databases with a lower priority (see Subsection 3.1) in order to investigate the FNC suitably. Consequently, if FNC is met, conflicting information is found; if FNC is not respected, the SNC can be considered as a sufficient condition for proving the emergence of success.

\subsubsection{How should conflicting information concerning success/failure be managed?}

Conflicting information appears when both FNC and SNC are met in the same or in different databases. It could be established to consider conflicting information as an indicator of a specific success category, 
namely disputable success, rather than trying to identify whether information addressing success or failure is predominant.

\subsubsection{Can success indicators be leveraged in order to get additional categories of success?}

In order to answer this question, a distinction can be first made between "direct" and "indirect" success, i.e. success suggested by clear statements or indirect indicators. The same circumstance does not apply for failure, as no clear indirect indicators have been found in the literature (see Section 2).

If it is opted to increase the granularity level of the characterization, it is worth noting that some indirect success indicators are argued in the literature. A possible further distinction can be made with regard to indirect successes indicators, namely between those that suggest the emergence of success and those that limit success to a special context (as suggested by the literature reading reported in Section 2).

Accordingly, it is possible to define criteria for establishing indirect indicators that address success supported by the literature, to be identified through the "indirect success suggesting condition" (ISSC), which addresses inferable success. Other indicators the scientific community has shown shortcomings on address the emergence of partial success. These might be recognized through the "indirect success limited condition" (ISLC), which indicates restricted success. For example, the ISSC can include:

- The existence of complementary products;

- The product is found into an imitation chain;

- Similar products are successful;

- A patent is exploited in order for a commercial product to work.

ISIC can reflect one or more of the following circumstances:

- The product has won an award;

- The product is displayed in a museum collection;

- The product is successful in a restricted niche market;

- The product is successful in a very limited geographical or social context.

Table 2. Summary of conditions and illustrative criteria for their fulfilment

\begin{tabular}{|c|l|l|l|}
\hline Condition & Acronym & \multicolumn{1}{|c|}{ Meaning } & Illustrative criterion to confirm the condition \\
\hline $\begin{array}{c}\text { Nesearch } \\
\text { Condition }\end{array}$ & RNC & $\begin{array}{l}\text { Condition that, if not met, allows the } \\
\text { product to be considered consigned to } \\
\text { oblivion }\end{array}$ & $\begin{array}{l}\text { Information about the product is present in } \\
\text { the selected databases }\end{array}$ \\
\hline $\begin{array}{c}\text { Maturity } \\
\text { Necessary } \\
\text { Condition }\end{array}$ & MNC & $\begin{array}{l}\text { Condition that, if not met, does not allow } \\
\text { product success to be evaluated }\end{array}$ & $\begin{array}{l}\text { The level of development or maturity of the } \\
\text { product permits a reliable evaluation of } \\
\text { success }\end{array}$ \\
\hline $\begin{array}{c}\text { Failure Sufficient } \\
\text { Condition }\end{array}$ & FSC & $\begin{array}{l}\text { Condition that, if met, allows the product } \\
\text { to be considered as a failure }\end{array}$ & $\begin{array}{l}\text { At least a bibliographic source claims } \\
\text { product failure }\end{array}$ \\
\hline $\begin{array}{c}\text { Success Sufficient } \\
\text { Condition }\end{array}$ & SSC & $\begin{array}{l}\text { Condition that, if met, allows the product } \\
\text { to be considered a success }\end{array}$ & $\begin{array}{l}\text { It is explicitly affirmed that the product is a } \\
\text { success, has thriven in the marketplace or its } \\
\text { development has given rise to outstanding } \\
\text { economic advantages }\end{array}$ \\
\hline $\begin{array}{c}\text { Failure Necessary } \\
\text { Condition }\end{array}$ & FNC & $\begin{array}{l}\text { Condition that, if not met, does not allow } \\
\text { the product to be considered as a failure }\end{array}$ & $\begin{array}{l}\text { Information about failure has emerged in the } \\
\text { selected databases }\end{array}$ \\
\hline $\begin{array}{c}\text { Success } \\
\text { Necessary } \\
\text { Condition }\end{array}$ & SNC & $\begin{array}{l}\text { Condition that, if not met, does not allow } \\
\text { the product to be considered as a success }\end{array}$ & $\begin{array}{l}\text { At least one of the relevant direct success } \\
\text { indicators is fulfilled in the databases }\end{array}$ \\
\hline $\begin{array}{c}\text { Indirect Success } \\
\text { Suggesting } \\
\text { Condition }\end{array}$ & ISSC & $\begin{array}{l}\text { Condition that, if met, allows the product } \\
\text { to be considered as an inferable success }\end{array}$ & $\begin{array}{l}\text { At least one of the relevant indirect success } \\
\text { indicators, unanimously supported by the } \\
\text { literature, emerges in the databases }\end{array}$ \\
\hline $\begin{array}{c}\text { Indirect Success } \\
\text { Limited } \\
\text { Condition }\end{array}$ & ISIC & $\begin{array}{l}\text { Condition that, if met, allows the product } \\
\text { to be considered as a restricted success }\end{array}$ & $\begin{array}{l}\text { At least one of the relevant indirect success } \\
\text { indicators, arguably supported by the } \\
\text { literature, emerges in the databases }\end{array}$ \\
\hline
\end{tabular}




\subsection{Description of the procedure and of success categories}

Further decisions have to be made regarding how to articulate the various conditions illustrated in 3.2 and what to deduce when they are met or unsatisfied. In this subsection, a structured search algorithm (underpinning the procedure) of product success characterization is proposed to the scope, as illustrated in Figure 1. In the figure, $\mathrm{N}$ is the priority index presented in Table 1 together with some illustrative examples. The outputs of the algorithm largely reflect the meaning attributed to the conditions summarized in Table 2 and described in the previous subsection.

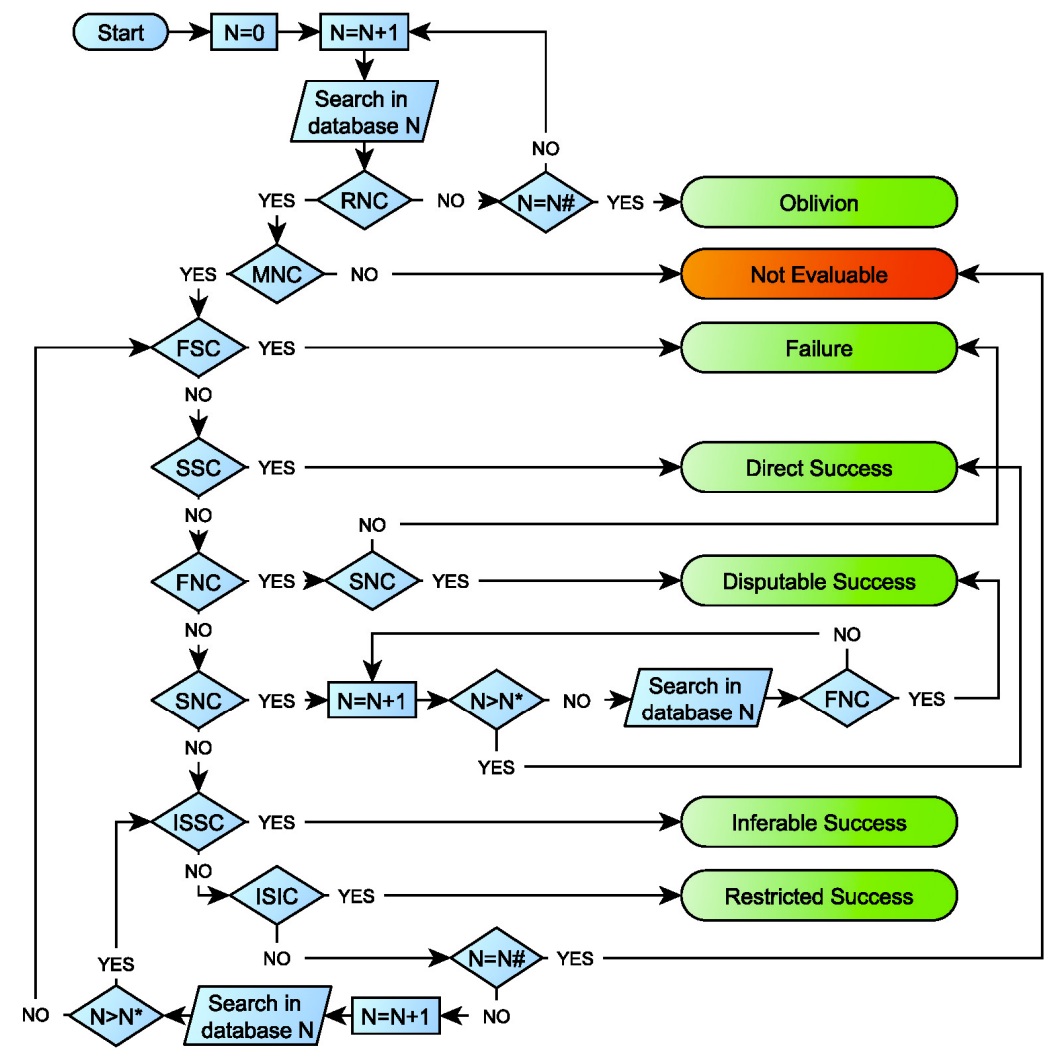

Figure 1. Algorithm underpinning the procedure for success characterization

The procedure foresees that the databases are browsed in order to determine whether the various conditions are satisfied. As a result, different success categories (in italics in the bullet list) can be extrapolated based on the relationships between sufficient and necessary conditions.

- Oblivion: no general product information emerges after the search in all the preselected databases, i.e. the RNC is not satisfied in any of the consulted databases.

- Not Evaluable: product information is found (RNC is met), but no information about success has emerged by searching in the preselected databases, or, in alternative, the MNC is not satisfied, because the maturity of the product is too low.

- Failure: it emerges when, in the database considered at a given step, the information found about the product undeniably affirms that it is a flop; this outcome is achieved by satisfying the FSC or meeting the FNC when the SNC is unfulfilled in the same priority database.

- Direct success: direct information about success is found, or, in alternative, uncontested indications have been individuated that suggest that the product is a success. With respect to listed conditions, this takes place when the SSC is satisfied or the SNC is met while the FNC is unmet in every database.

- Disputable success: it emerges when conflicting information about success and failure is found. Both the SNC and FNC are satisfied. By observing Figure 1, it is apparent that the reliability of 
information about failure is considered high even if found in databases with lower priority to the ones addressing product success.

- Inferable success: success is suggested by information showing that undisputed indirect success indicators are fulfilled. The ISSC is satisfied.

- Restricted success: success is suggested by information showing that argued indirect success indicators are fulfilled. The ISIC is satisfied.

Apart from not evaluable success, it is possible to distinguish six characterizations of success. With the exception of oblivion, other sets are ascribable to the database that allowed the characterization of success.

On the one hand, the procedure allows the researcher to obtain a high level of differentiation in success characterization based on both fulfilled criteria and explored databases. On the other hand, a high level of differentiation could be useless for the aim of the research. For this reason, the granularity of the classification, obtained by possibly subdividing some categories, has to match the scopes of one's study. For instance, by considering the illustrative databases shown in the Table 1, it is possible to cluster the information from Scopus and Google Scholar as databases based on the literature and keep their differentiation with respect to Google search, as a general search engine in the web.

\section{Product success information: Use case}

As introduced in the first section, the necessity to characterize the success commonly arises in order to link product features with the success achieved. Success has been considered as a dummy variable in other works, but a more detailed characterization, as obtained through the procedure proposed, enables the consideration of multiple nuances of success and more insightful statistical analysis.

In order to check the distribution balance between the categories with the level of granularity featured by the algorithm outputs of Figure 1, the authors have analysed 178 products implementing sustainable principles extracted by books and public databases. In this specific analysis, the measures that follow have been taken:

- The consulted databases are those listed in Table 1.

- It has been checked whether the product, featured by its commercial name, is known in alternative ways.

- The search for information about the product maturity was supported by use of search terms such as "Matur*", "Prototyp*", "Year of release", "Develop*" (the symbol * denotes that the terms have been used as possible word stems hereinafter).

- The search for possible information about the product success was supported by use of search terms such as "Success*", "Thriv*", "Triumph*", "Breakthrough", "Revenue", "Satisf*", "Outstanding", "Perform*".

- The search for possible information about the product failure was supported by use of search terms such as "Fail*", "Unsuccess*", "Fiasco", "Breakdown", "Malfunction", "Flop", "Underachiev*", "Disappoint*", "Nonfulfil*", "Shortcoming".

- The monitoring of information concerning indirect success indicators was supported by use of search terms such as "Complement*", "Imitat*", "Similar*", "Niche", "Award*".

- The search for information about similar, complementary and imitating products was conducted also by making reference to the function, characteristics and benefits of the product instead of using just the commercial or alternative names, e.g. modular bed, lightweight detergent packaging.

- Imitations were considered relevant just within the same industry of the surveyed product.

- When relevant to browse patent databases, the name of the product manufacturer was used in the assignee search field by using Esp@cenet, so that companies' patent portfolios have been explored.

The use of the procedure and the above measures gave rise to the possible classification of all the 178 products. None of them was considered as "not evaluable", as the products were extracted from not too recent sources including datasets of sustainable designs. The outputs in terms of success are as follows: 
6 are consigned to the oblivion, 2 are failures, 8 are disputable, 12 are restricted, 43 are inferable, 107 are direct successes. The predominance of successful examples illustrated in the literature is largely confirmed by the analysis. Based on this evidence and with the aim to balance success categories, direct successes were split according to the reliability of the sources in which information about success was found. This resulted in distinguishing between:

- Information found in Scopus or Google Scholar, giving rise to the category "Literature success" - 70 items belong to this category;

- Information found in other databases, giving rise to the category "Web success" - 37 items belong to this category.

Further distinctions or aggregations were deemed awkward, but, of course, different adaptations to the categorization process can be made.

\section{Verification of an ordinal scale for product success}

Given the final categories emerged from the above analysis, the authors have individuated a possible scale by logic, which is shown below ordered in ascending success levels.

1. Failure (to be interpreted through the description of Product $\mathrm{G}$ in Table 3 ).

2. Oblivion (to be interpreted through the description of Product A in Table 3).

3. Disputable Success (to be interpreted through the description of Product B in Table 3).

4. Restricted Success (to be interpreted through the description of Product F in Table 3).

5. Inferable Success (to be interpreted through the description of Product $\mathrm{C}$ in Table 3).

6. Web Success (to be interpreted through the description of Product D in Table 3).

7. Literature Success (to be interpreted through the description of Product E in Table 3).

The creation of a set of ordinal variables instead of nominal variables allows the provision of more insightful results in statistical tests. However, this success scale could not be fully demonstrated through literature information. Consequently, a questionnaire with the general descriptions of the kind of achieved success arranged in random order has been fine-tuned and subsequently administered.

Eight experts with more than 10 years of experience in engineering design or NPD management have been asked to order the categories based on their perception of success. More precisely, the assigned task was to complete a copy of the following Table 3 based on the input below.

- You can find below a series of different products, which will not be revealed, that have been grouped in different categories according to the information found about their "success". According to your perception of the "success" concept, please order from 1 (minimum success) to 7 (maximum success) the products listed in the table by filling the right-hand column.

Table 3. Copy of the table to be filled by involved experts in NPD in order to check the reliability of the success scale hypothesized by the authors

\begin{tabular}{|c|c|c|}
\hline Product & Description of the outcome of the search about success & $\begin{array}{c}\text { Success } \\
\text { level }\end{array}$ \\
\hline A & $\begin{array}{l}\text { Information about the product is not found; it is possible to infer that the product } \\
\text { has been consigned to oblivion }\end{array}$ & \\
\hline B & $\begin{array}{l}\text { Conflicting information is found (in the literature or in the Internet) about the } \\
\text { product and/or the performances the product was meant to achieve }\end{array}$ & \\
\hline $\mathrm{C}$ & $\begin{array}{l}\text { Direct information about the product success is not found, but the product fulfils } \\
\text { success criteria that are agreed by the scientific community }\end{array}$ & \\
\hline $\mathrm{D}$ & Many web sources affirm that the product is/has been successful & \\
\hline $\mathrm{E}$ & Scientific sources affirm that the product is a success & \\
\hline $\mathrm{F}$ & $\begin{array}{l}\text { Direct information about the product success is not found, but the product fulfils } \\
\text { success criteria that are, however, not unanimously agreed by the scientific } \\
\text { community }\end{array}$ & \\
\hline G & Bibliographic sources affirm that the product is/has been unsuccessful & \\
\hline
\end{tabular}


In this way, the authors achieved Inter-Rater Reliability (IRR) coefficients for each pair of categories. Table 4 reports IRR values when considering the products belonging to the success category in a row more successful than those featured by reference category reported in the corresponding column. For instance, considering Inferable success larger than disputable success was agreed by $87.5 \%$ of the involved experts. The outcomes show that the scale hypothesized by the authors has a good consensus; this makes it possible to consider the seven success levels as ordinal variables despite missing justifications from the literature.

Table 4. IRR concerning the greater level of success reported by the category featuring the row with respect to the one featuring the column

\begin{tabular}{|c|c|c|c|c|c|c|}
\hline More successful than $->$ & Web & Inferable & Restricted & Disputable & Oblivion & Failure \\
\hline Literature & 0.75 & 1 & 1 & 1 & 1 & 1 \\
\hline Web & & 0.75 & 0.75 & 1 & 1 & 1 \\
\hline Inferable & & & 1 & 0.875 & 1 & 1 \\
\hline Restricted & & & & 0.875 & 1 & 1 \\
\hline Disputable & & & & & 1 & 1 \\
\hline Oblivion & & & & & & 0.75 \\
\hline
\end{tabular}

\section{Summary of the work and final remarks}

The findings of the present paper aim to facilitate research in product design where the evaluation of success is a relevant aspect, especially when this parameter has to be studied through statistical techniques. Indeed, this contribution is motivated by the need (experienced by the authors as well) to take into consideration product success as a dependant variable of engineering design activities and choices. A shared measure of success has not been defined so far and this poses limitations to studies aimed to maximize the likelihood of new products to achieve success. Success is diffusedly considered as the manifestation of positive financial results, but those to focus on primarily and the limited availability of this kind of data are critical issues. Starting from these considerations, the authors investigated the opportunity to browse available information about products in order to characterize their achieved success. The outcome of this work is constituted by a procedure that allows any potential user to determine the most appropriate success category for any product. This procedure, depicted through the algorithm illustrated in Figure 1, is swivelled on the satisfaction of a number of conditions and the choice of the databases in which reliable information is supposed to be found. In order to apply the procedure in a rigorous way, any researcher should define the criteria on which to base the compliance with any condition. The choices put forward by the authors are exposed in an illustrative form, but can be questioned and/or adapted to specific tasks. This aspect lays bare that the process of characterizing success, although guided through the proposed procedure, is supported empirically previous experience might play a significant role in decisions to make during the whole process. Further measures have been proposed (Section 4) in order to support the extraction of relevant information.

The authors have individuated six main categories of success (when this is evaluable), which are based on the availability of sufficient information, direct information about success, fulfilment of success indicators that are agreed in the literature to different extents. These categories can be aggregated or split, for instance based on the distinction among the indicators leveraged to infer success or the reliability of sources stating success of given products. In a practical experiment in which 178 products have been analysed, the authors have subdivided the category of evident success into a class for which information is available in scientific literature and another subset concerning declarations of success restricted to non-reviewed web sources. The resulting seven categories have been attributed an ordinal meaning, as the numbered list of Section 5 clarifies. The possibility to use these success categories as ordinal variables is confirmed by the opinion of eight involved experts.

As recalled, the authors have checked the usability of the procedure, but the use of the ensuing results is still to be fully experimented. Future work will concern matching the emerged categories of success (intended as a dependent variable) with the sustainable design principles (intended as independent 
variables) that have been implemented by the mentioned 178 products. The aim is to identify principles that favour or hinder the manifestation of success. It is expected that this study will provide more insightful information than an alternative in which the sole distinction between success and failure is used. Of course, further employments of the procedure and the scale are expected.

Eventually, some methodological limitations are discussed. It has been already highlighted that the procedure requires several choices, hence a certain extent of subjectivity, to work properly. However, this is deemed acceptable, as the procedure represents a first proposal in the design field, in which the systematic determination of success has been absolutely overlooked so far. Another shortcoming might concern the disregard of popularity of information about product's success or failure. In the current version of the algorithm, the presence of information about failure and success is checked sequentially in a given database, instead of evaluating the number of sources coming to certain conclusions. A more automatized procedure, in which criteria to satisfy the conditions are established, could take into consideration the predominance of information inferring success or failure. Text mining and parsing techniques might undeniably benefit such an objective. At the same time, with the increasing diffusion of social media, some indicators (such as Facebook likes) could be used as an alternative or support to the procedure, although this is unlikely to work with old products.

Readers interested or willing to replicate the experiment to evaluate the repeatability of the procedure can contact the authors in order to get more details about the procedure and the list of products employed to test the applicability of the method for the determination of success.

\section{References}

Bender, B. and Marion, S. (2016), "Dimensions of product development success", DS 84: Proceedings of the DESIGN 2016 / 14th International Design Conference, Cavtat-Dubrovnik, Croatia, May 16-19, 2016, The Design Society, Glasgow, pp. 1455-1464.

Borgianni, Y., Cascini, G., Pucillo, F. and Rotini, F. (2013), "Supporting product design by anticipating the success chances of new value profiles", Computers in Industry, Vol. 64 No. 4, pp. 421-435. https://doi.org/10.1016/j.compind.2013.02.004

Bourgeon, L. (2007), "Staffing approach and conditions for collective learning in project teams: The case of new product development projects", International Journal of Project Management, Vol. 25 No 4, pp. 413-422. https://doi.org/10.1016/j.ijproman.2007.01.014

Calcei, D. and Ohana, M. (2017), "The Influence of the Adult Entertainment Industry on Technology Standards for Computer, Video, and Smartphone Applications”, Global Business and Organizational Excellence, Vol. 36 No. 3, pp. 14-20. https://doi.org/10.1002/joe.21776

Cooper, R.G. and Kleinschmidt, E.J. (1987), "Success factors in product innovation", Industrial marketing management, Vol. 16 No. 3, pp. 215-223. https://doi.org/10.1016/0019-8501(87)90029-0

Dinter, B. (2013), "Success factors for information logistics strategy-An empirical investigation", Decision Support Systems, Vol. 54 No. 3, pp. 1207-1218. https://doi.org/10.1016/j.dss.2012.09.001

Faerber, S.J. and Carbon, C.C. (2013), "Jump on the innovator's train: cognitive principles for creating appreciation in innovative product designs", Research in Engineering Design, Vol. 24 No. 3, pp. 313-319. https://doi.org/10.1007/s00163-012-0148-7

Griffin, A. and Page, A.L. (1993), "An interim report on measuring product development success and failure", Journal of product innovation management, Vol. 10 No. 4, pp. 291-308. https://doi.org/10.1016/07376782(93)90072-X

Griffin, A. and Page, A.L. (1996), "PDMA success measurement project: recommended measures for product development success and failure", Journal of product innovation management, Vol. 13 No. 6, pp. 478-496. https://doi.org/10.1016/S0737-6782(96)00052-5

Haig, M. (2005), Brand failures: the truth about the 100 biggest branding mistakes of all time, Kogan Page Publishers, London, UK.

Hart, S. (1993), "Dimensions of success in new product development: an exploratory investigation", Journal of marketing management, Vol. 9 No. 1, pp. 23-41. https://doi.org/10.1080/0267257X.1993.9964215

Hernandez, N.V., Schmidt, L.C., Kremer, G.O. and Lin, C.Y. (2014), “An empirical study of the effectiveness of selected cognitive aids on multiple design tasks", Design Computing and Cognition '12, Springer, Dordrecht, pp. 227-246. https://doi.org/10.1007/978-94-017-9112-0_13

Hsiao, Y.C., Chen, C.J., Guo, R.S. and Hu, K.K. (2017), "First-mover strategy, resource capacity alignment, and new product performance: a framework for mediation and moderation effects", R\&D Management, Vol. 47 No 1, pp. 75-87. https://doi.org/10.1111/radm.12157 
Hultink, E.J. and Robben, H.S. (1995), "Measuring new product success: The difference that time perspective makes", Journal of product innovation management, Vol. 12 No. 5, pp. 392-405. https://doi.org/10.1016/07376782(95)00055-0

Lockwood, T. (2007), “Design value: A framework for measurement”, Design Management Review, Vol. 18 No. 4, pp. 90-97. https://doi.org/10.1111/j.1948-7169.2007.tb00099.x

Machado, R.B. (2016), "Design Management and Business Success: The Emerging Connection”, Design Management Review, Vol. 27 No. 2, pp. 44-49. https://doi.org/10.1111/drev.12009

Maidique, M.A. and Zirger, B.J. (1985), "The new product learning cycle", Research policy, Vol. 14 No. 6, pp. 299-313. https://doi.org/10.1016/0048-7333(85)90001-0

McGee, J. and Sammut-Bonnici, T. (2002), "Network industries in the new economy", European Business Journal, Vol. 14 No. 5, pp. 116-32.

Moatari Kazerouni, A., Achiche, S., Hisarciklilar, O. and Thomson, V. (2011), "Influence of the time perspective on new product development success indicators", Proceedings of ICED 11 / 18th International Conference on Engineering Design, Lyngby-Copenhagen, Denmark, August 15-19, 2011, The Design Society, Glasgow, pp. 40-51.

Nyström, H. (1985), "Product development strategy: An integration of technology and marketing", Journal of Product innovation management, Vol. 2 No. 1, pp. 25-33. https://doi.org/10.1111/1540-5885.210025

Rainer, A. and Strohmaier, R. (2014), "Modeling the diffusion of general purpose technologies in an evolutionary multi-sector framework", Empirica, Vol. 41 No. 3, pp. 425-444, https://doi.org/10.1007/s10663-014-9264-0

Rampino, L. (2011), "The innovation pyramid: A categorization of the innovation phenomenon in the productdesign field”, International Journal of Design, Vol. 5 No.1, pp. 3-16.

Song, C., Luo, J., Hölttä-Otto, K., Seering, W. and Otto, K. (2015), "Risk and Innovation Balance in Crowdfunding New Products", Proceedings of ICED 15 / 20th International Conference on Engineering Design, Milan, Italy, July 27-30, 2015, The Design Society, Glasgow, pp. 1-10.

Troxell, P.M. and Kim, C. (2016), "A method for classifying products designed for the developing world", Proceeding of ASME 2016 / International Design Engineering Technical Conferences and Computers and Information in Engineering Conference, Charlotte, North Carolina, USA, August 21-24, 2016, American Society of Mechanical Engineers. https://doi.org/10.1115/DETC2016-60522

Dr.-Ing. Yuri Borgianni, Contract Researcher

Free University of Bozen-Bolzano, Faculty of Science and Technology

Piazza Universitá 5; Universitätplatz 5, 39100 Bolzano-Bozen, Italy

Email: yuri.borgianni@unibz.it 